\title{
Artificial Intelligence Design Waterfronts and Particular Places Management to Improve Relationships between People
}

\author{
Shekufe Mottaghi \\ The PHD student of psychology, the professor of shahrekord non-profitable university, Is lamic Azad University \\ Sharekord Branch, Iran \\ E-mail: fatemeh_farhadi_designer@yahoo.com
}

Fatemeh Farhadi

Department of Architect and Educational, Is lamic Azad University Sharekord Branch, Iran E-mail: fatemeh_farhadi_designer@yahoo.com

Samira Dokohaki

Department of Architect and Educational, Islamic Azad University Sharekord Branch, Iran E-mail: fatemeh_farhadi_designer@yahoo.com

Mohammad Mohsen Farhadi

Department of Civil Engineering, Islamic Azad University Yasouj Branch, Iran E-mail: fatemeh_farhadi_designer@yahoo.com

\begin{abstract}
Tourist attraction was used to achieve a stable waterfront, while the fuzzy-logic added intelligence to the select strategy through an automatic selection of the tourist attraction coefficient. This paper examines the relationship between heritage sites, waterfronts, and relationships between people in present-day in urban culture. Urban waterfronts are important and special assets and that, when redeveloped, they often contribute to healthy traditional communities. Waterfronts can serve as a unifying force in a city or town and can be, and often are, a force for community enrichment. Further, vibrant communities are essential for environmental, economic and social advancement. There are several strategy specific principles as a way to improve of usage from particular places and waterfront city. Select and design the best strategy play important role to tourist attraction. Fuzzy logic inference system is used to select the best methodology and based on this research and fuzzy logic method, striped methodology is used to have a best performance.
\end{abstract}

Index Terms - Fuzzy Logic Theory, Waterfront, Traditional Community, Heritage Site, Striped Methodology, Healthy Community

\section{Introduction}

Who benefits and/or profits from these waterfronts Performances and their use values? Not surprisingly, people enjoyed learning about particular places with the power of memories and experiences. Examining the ways in which these places teach about and shape relationships between people, place, and identity generally are important. Many famous theorists of cultural landscapes, makes an explicit connection between cultural landscape studies, theories of space and place, and tourism. It is about loyalty to local community, and the relationship of people to tourist attractions.

Tourist narratives exist to promote a given place as a "destination"- a site that is attractive, noteworthy and offers services that will keep visitors satisfied as they explore and learn. If touris $\mathrm{m}$ and education promotes pride of place, it also boosts local economies, so it is not surprising that most narratives associated with tourist and education destinations are positive and upbeat, often celebratory of events, populations, and structures. But cultural and historic touris ms pose some particular challenges to this dominant model. As cultural and historical tourism narratives evolve, they often shift, forced to integrate new ideas in ways that visitors will still find palatable and accessible. Accordingly, even dominant tourists narratives prove exceedingly flexible as they absorb, integrate or, in some cases, co-opt and transform alternative narratives.

An analysis of any waterfront city is incomplete without first including a brief background to the development of waterfront cities in general. During the early to mid 1900 's, waterfront's downtown population 
decreased and moved to the mainland to live, and commuted back to the city to work. This resulted in many vacant sites which still exist in the downtown core of waterfront city. The main reas on for this is the industrial revolution, which resulted in a decrease of industrial and consumer activities that once operated at a human scale along city waterfronts, such as local markets supplied by harbor related industry like fishing and transporting goods. Another reas on is the economic value of downtown property was increasing and became too expensive to compete with the inviting characteristics of suburban living. In addition to this, there were general social perspectives towards family living conditions which generated conflicts between high densities, shared accommodation of city building typology. The final, and perhaps the most important reason of all, which also made suburban lifestyles possible, is the advancements of the automobile and the monopoly over the transportation industry the oil companies created around the 1940's. The vast affects of the industrial revolution almost entirely eliminated designing cities based on scale, proximity and proportion of the human body [1-3]. Today and over the past few decades, the benefits of city living has generated more interest within society. The increasing costs of transportation and suburban zoning and bylaws have become more problematic than beneficial and sustainable [1]. Previous social views of 'proper' family living are being challenged. New housing prototypes and developments are accommodating issues of privacy, ownership and community within dense urban sites. Designing urban infrastructure and buildings with a holistic approach is being further investigated and emphasized. The benefits of mixed use developments have become widely recognized and in some cases mandatory [2-4]. First a brief study of waterfront cities in general will allow the Halifax waterfront and this thesis to be placed within a formal and historical context. Around the 1960's is when most urban waterfront redevelopment took place. Shifting from what was previously seen as an area that was strictly for industry, transportation, fishing and flood protection. Now leisure is becoming increasingly important to waterfronts and the process of deindustrialization is opening up vast new territories. Waterfronts have a dramatic and visible impact that is capable not only of enriching a city's economy but of improving its collective self-image [1-6].

Fuzzy-logic aims to provide an approximate but effective means of describing the behavior of systems that are not easy to describe precisely, and which are complex or ill-defined. It is based on the assumption that, in contrast to Boolean logic, a statement can be partially true (or false). For example, the expression (I live near Halifax) where the fuzzy value (near) applied to the fuzzy variable (distance), in addition to being imprecise, is subject to interpretation. The essence of fuzzy optimize is to build a model of human expert who is capable of optimizing the methodology without thinking in terms of its mathematical model. As opposed to conventional optimize approaches where the focus is on constructing a optimizer described by differential equations, in fuzzy optimize the focus is on gaining an intuitive understanding (heuristic data) of how to best optimize the process, and then load this data into the optimize the best methodology.

By considering the waterfront area as a threshold between the city grid and harbour, there are a few simple options that can form basic strategies or principles applicable to waterfront cities, which can then be further developed. The basic organization of Halifax's waterfront is used as a template. It is important to make a clear decision with one strategy so the waterfront area is treated as a coherent whole and may create an image for the entire city. A strategy should be chosen based on the historical and contemporary conditions of each city and based on these parameters fuzzy inference system is used to select the best methodology. Typology studies of each strategy are; extended the grid, alternating gride and parks, object buildings in the park and striped building and parks. Based on above discussion Mamdani fuzzy inference engine is used to select the best methodology for our case study (e.g., Halifax).

Accordingly, this paper examines the relationship between historic tourism and economic redevelopment in present-day waterfront, evaluating how cultural heritage narratives are informed by eighteenth, nineteenth and early twentieth-century labor histories and subsequently presented to both residents and visitors for the purposes of education and cultural enrichment and finally select the fuzzy rule base to select the best methodology to design attractive waterfront in Halifax.. Considering the adaptive reuse of former places of industry as tourist attractions, traditionally understood as contemporary sites of leisure, researcher argues that local tourist narratives have both transnational origins and transnational impacts on the flows of capital and human bodies (particularly those of peripheral or traditionally marginalized populations) within the increasingly de-industrialized economy of the global West. While many tourists certainly visit the waterfronts the other places enjoy the annual County Fair, with its events and exhibits, log-rolling contests, live musical entertainment and animal auctions, this area does not yet feature a large number of tourist attractions, one coherent interpretive tourist narrative or an organized network of heritage touris m management. Therefore fuzzy inference system with two inputs (error and error rate) and one output (tourist attraction) is design and application to select the best methodology.

This paper is organized as follows; section 2, is served as an introduction to the fuzzy logic optimization, waterfronts strategies. Part 3, introduces and describes the methodology. Section 4 presents the applied fuzzy optimized methodology to Halifax and the final section is describing the conclusion. 


\section{Theory}

Waterfront Strategies: By considering the waterfront area as a threshold between the city grid and harbour, there are a few simple options that can form basic strategies or principles applicable to waterfront cities, which can then be further developed. The basic organization of Halifax's waterfront is used as a template. It is important to make a clear decision with one strategy so the waterfront area is treated as a coherent whole and may create an image for the entire city. A strategy should be chosen based on the historical and contemporary conditions of each city. Typology studies of each strategy are described on the following;

Strategy 1 -Extend the Grid: Establishing a continuous streetscape, only pushes the grid farther into the waterfront public park. The typology of this strategy lends itself to mid-rise buildings with an emphasis on density and infill. The grid axis loses direction and intention as it enters the public park. Although I don't believe this strategy is suitable for any city waterfront, it can be most related to the waterfront sites of London and Amsterdam, where density plays a major role in waterfront development.

Strategy 2- Alternating Grid and Parks: A simple alternating pattern of streetscape and open public parks. Mid-rise courtyard buildings can be suitable for the dense blocks of infill. The main concern is the potential for privatisation of park areas where the dense blocks are positioned and the creation of parks that may not provide any shelter. The axis of the grid begins to rotate perpendicular to the harbour as it enters the parks. This strategy may lend itself to long waterfront sites.

Strategy 3 - Object Buildings in the Park: Conceive the waterfront threshold as a large public park with 'object-like' buildings floating free of the grid and streetscape. High-rise buildings may enforce their presence as objects within the ground plane park. The main concern is the high buildings might create a sense of hierarchy and ownership over the public park. The high-rises can be considered too private on waterfront cities, which goes against the argument of this paper. The grid axis change direction around the buildings, no longer extending the grid or making perpendicular connections between the city and harbour. This strategy seems most appropriate to very large cities with grids that are not orthogonal to the harbour, such as Manhattan. No order of building location, uninviting to the public sector.

Strategy 4 - Striped Buildings and Parks: A 'striped' strategy alternates between buildings and parks perpendicular to the harbour. Low, horizontal buildings are most beneficial to this strategy. As the city typology meets the waterfront area, tall buildings are rotated to become low and narrow, creating an equality of height throughout the waterfront. Spacing of the buildings allows equal sun penetration to the ground and plane and creates many opportunities for movement between the city and harbour. Grid axes are strongly extended all the way to the water and remain perpendicular in direction.

Fuzzy Inference Engine: This section provides a review about foundation of fuzzy logic based on [1421]. Supposed that $U$ is the universe of discourse and $x$ is the ele ment of $U$, therefore, a crisp set can be defined as a set which consists of different elements $(x)$ will all or no me mbership in a set. A fuzzy set is a set that each element has a membership grade, therefore it can be written by the following definition;

$$
A=\left\{x, \mu_{A}(x) \mid x \in X\right\} ; A \in U
$$

Where an element of universe of discourse is $x, \mu_{A}$ is the membership function (MF) of fuzzy set. The membership function $\left(\mu_{A}(x)\right)$ of fuzzy set $A$ must have a value between zero and one. If the membership function $\mu_{A}(x)$ value equal to zero or one, this set change to a crisp set but if it has a value between zero and one, it is a fuzzy set. Defining membership function for fuzzy sets has divided into two main groups; namely; numerical and functional method, which in numerical method each number has different degrees of membership function and functional method used standard functions in fuzzy sets. The membership function which is often used in practical applications includes triangular form, trapezoidal form, bell-shaped form, and Gaussian form.

Linguistic variable can open a wide area to use of fuzzy logic theory in many applications (e.g., optimization). In a natural artificial language all numbers replaced by words or sentences.

If - then Rule statements are used to formulate the condition statements in fuzzy logic. A single fuzzy If - then rule can be written by

$$
\text { If } x \text { is } A \text { Then } y \text { is } B
$$

where $A$ and $B$ are the Linguistic values that can be defined by fuzzy set, the If - part of the part of " $x$ is $A$ " is called the antecedent part and the then part of the part of " $y$ is $B$ " is called the Consequent or Conclusion part. The antecedent of a fuzzy if-then rule can have multiple parts, which the following rules shows the multiple antecedent rules:

\section{if $e$ is $H$ and $e$ is $M$ then $T A$ is $B$}

where $e$ is error, $\dot{e}$ is error rate, $H$ is High, $M$ is Medium $T A$ is tourist attraction and $B$ is bad. If - then rules have three parts, namely, fuzzify inputs, apply fuzzy operator and apply implication method which in fuzzify inputs the fuzzy statements in the antecedent replaced by the degree of me mbership, apply fuzzy operator used when the antecedent has multiple parts and replaced by single number between 0 to 1 , this part is a degree of support for the fuzzy rule, and apply implication method used in consequent of fuzzy rule to replaced by 
the degree of membership. The fuzzy inference engine offers a mechanism for transferring the rule base in fuzzy set which it is divided into two most important methods, namely, Mamdani method and Sugeno method. Mamdani method is one of the common fuzzy inference systems and he designed one of the first fuzzy controllers to control of system engine [15-19]. Mamdani's fuzzy inference system is divided into four major steps: fuzzification, rule evaluation, aggregation of the rule outputs and defuzzification. Mich io Sugeno use a singleton as a membership function of the rule consequent part. The following definition shows the Mamdani and Sugeno fuzzy rule base [20]

$$
\begin{aligned}
& \text { Mamdani F. } R^{1}: \text { if } \quad x \text { is } A \text { and } \\
& y \text { is } B \text { then } z \text { is } C \\
& \text { Sugeno F. } R^{1} \text { if } x \text { is A and } \\
& y \text { is } B \text { then } f(x, y) \text { is } C
\end{aligned}
$$

When $x$ and $y$ have crisp values fuzzification calculates the membership degrees for antecedent part. Rule evaluation focuses on fuzzy operation $(A N D / O R)$ in the antecedent of the fuzzy rules. The aggregation is used to calculate the output fuzzy set and several methodologies can be used in fuzzy logic controller aggregation, namely, Max-Min aggregation, Sum-Min aggregation, Max-bounded product, Max-drastic product, Max-bounded sum, Max-algebraic sum and Min-max. Two most common methods that used in fuzzy logic controllers are Max-min aggregation and Sum-min aggregation. Max-min aggregation defined as below

$$
\begin{aligned}
& \mu_{U}\left(x_{k}, y_{k}, U\right)=\mu_{\cup i=1}^{r} F R^{i}\left(x_{k}, y_{k}, U\right) \\
& =\max \left\{\operatorname { m i n } _ { i = 1 } ^ { r } \left[\mu_{R} p q\right.\right. \\
& \left.\left.\left(x_{k}, y_{k}\right), \mu_{p_{m}}(U)\right]\right\}
\end{aligned}
$$

The Sum-min aggregation defined as below

$$
\begin{aligned}
& \mu_{U}\left(x_{k}, y_{k}, U\right)=\mu_{\cup U_{i=1}^{r} F R^{i}}\left(x_{k}, y_{k}, U\right) \\
& =\sum \min _{i=1}^{r}\left[\mu_{R p q}\left(x_{k}, y_{k}\right), \mu_{p_{m}}(U)\right]
\end{aligned}
$$

where $r$ is the number of fuzzy rules activated by $x_{k}$ and $y_{k}$ and also $\mu_{\cup_{i=1}^{r} F R^{i}}\left(x_{k}, y_{k}, U\right)$ is a fuzzy interpretation of $i-t h$ rule. Defuzzification is the last step in the fuzzy inference system which it is used to transform fuzzy set to crisp set. Consequently defuzzification's input is the aggregate output and the defuzzification's output is a crisp number. Centre of gravity method $(C O G)$ and Centre of area method (COA) are two most common defuzzification methods, which COG method used the following equation to calculate the defuzzification

$$
\operatorname{COG}\left(x_{k}, y_{k}\right)=\frac{\sum_{i} U_{i} \sum_{j=1}^{r} \cdot \mu_{u}\left(x_{k}, y_{k}, U_{i}\right)}{\sum_{i} \sum_{j=1}^{r} \cdot \mu_{u}\left(x_{k}, y_{k}, U_{i}\right)}
$$

and $C O A$ method used the following equation to calculate the defuzzification

$$
\operatorname{COA}\left(x_{k}, y_{k}\right)=\frac{\sum_{i} U_{i}, \mu_{u}\left(x_{k}, y_{k}, U_{i}\right)}{\sum_{i} \mu_{U} \cdot\left(x_{k}, y_{k}, U_{i}\right)}
$$

Where $\operatorname{COG}\left(x_{k}, y_{k}\right)$ and $\operatorname{COA}\left(x_{k}, y_{k}\right)$ illustrates the crisp value of defuzzification output, $U_{i} \in U$ is discrete element of an output of the fuzzy set, $\mu_{U} \cdot\left(x_{k}, y_{k}, U_{i}\right)$ is the fuzzy set membership function, and $r$ is the number of fuzzy rules.

Based on foundation of fuzzy logic methodology; fuzzy $\log$ ic controller has played important rule to design optimization device for tourist attraction [21]. However the application area for fuzzy inference is really wide, the basic form for all command types of fuzzy inference engine consists of;

- Input fuzzification (binary-to-fuzzy[B/F]conversion)

- Fuzzy rule base (knowledge base)

- Inference engine

- Output defuzzification (fuzzy-to-binary [F/B] conversion).

Figure 1 shows the fuzzy logic inference system to optimize systems.

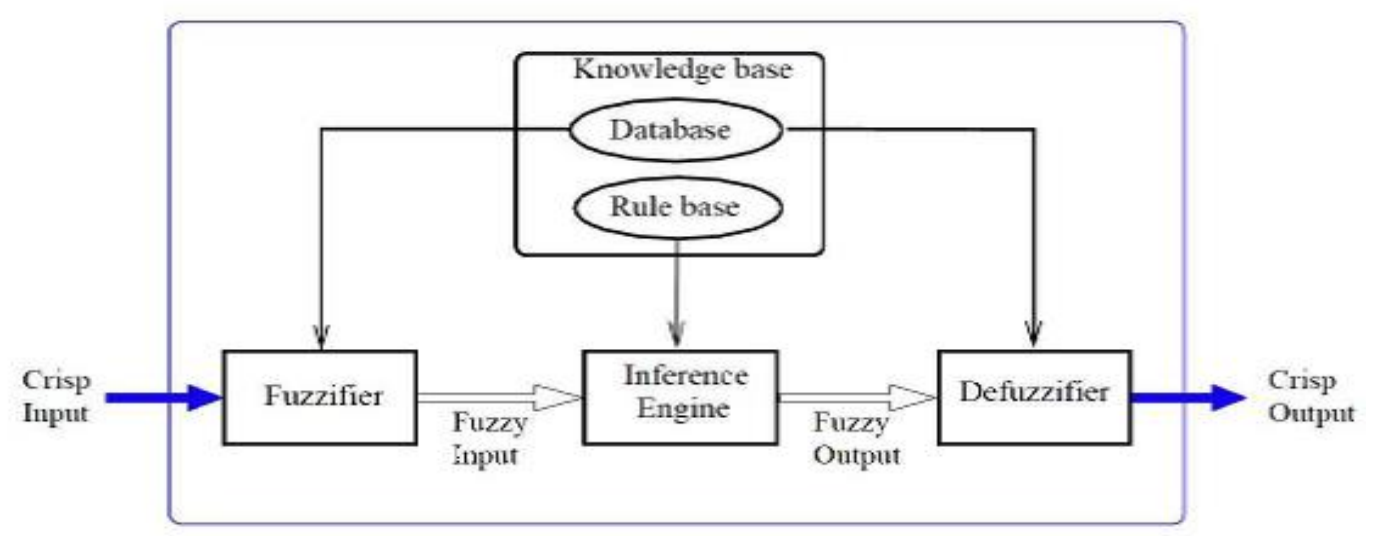

Fig. 1: Implementation of fuzzy-logic optimization system, adapted from 


\section{Methodol ogy}

The synthesis of the fuzzy-logic optimization in the current work will be limited to the intelligent tracking of the flatness control's desired data. This will be established by implementing an on-line tuning of the best output at each excitation tourist attraction parameters without recourse to the tedious and time consuming tasks of re-calculating them using the MATLAB command PLACE. The functionality of the FLS is exploited in the current work to solve for the robust fuzzy-flatness tracking optimization as shown in Figure 2.

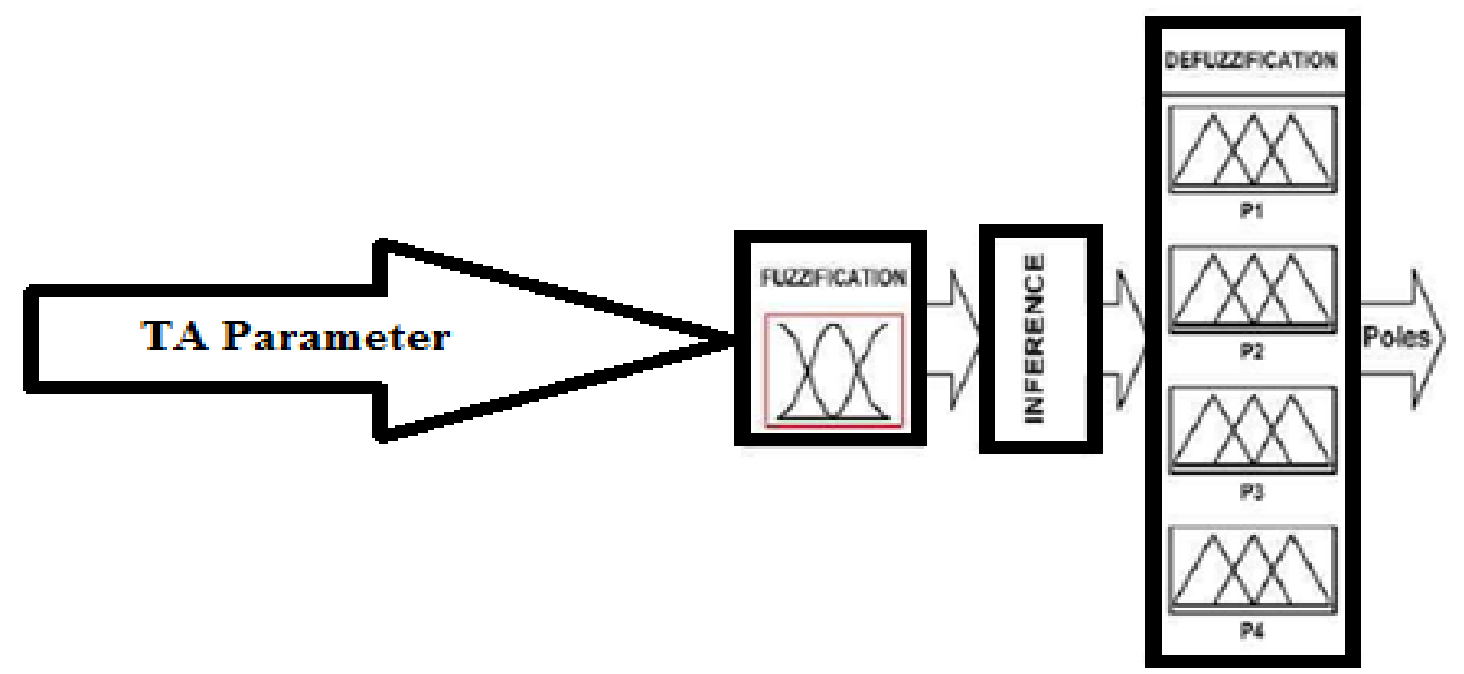

Fig. 2: Fuzzy-logic solution of the flatness tracking optimization

The pole placement coefficients $(K i j)$ are the outputs, while the actual poles are predefined and located in the left side of the complex plane to ensure stability. The excitation tourist attraction parameters $\left(f_{\text {ext }}\right)$ are selected to be the input fuzzy variable, which takes values in the range. This excitation tourist attraction parameters $\left(f_{\text {ext }}\right)$, must be first fuzzified by creating membership values to put them into fuzzy sets through the use of membership functions. In the current work, the researcher use the triangular me mbership function, which seems to be more efficient from a real-time implementation view point than the Gaussian function. The input membership function of the tourist attraction parameters $\left(f_{\text {ext }}\right)$ is shown in Figure 3.

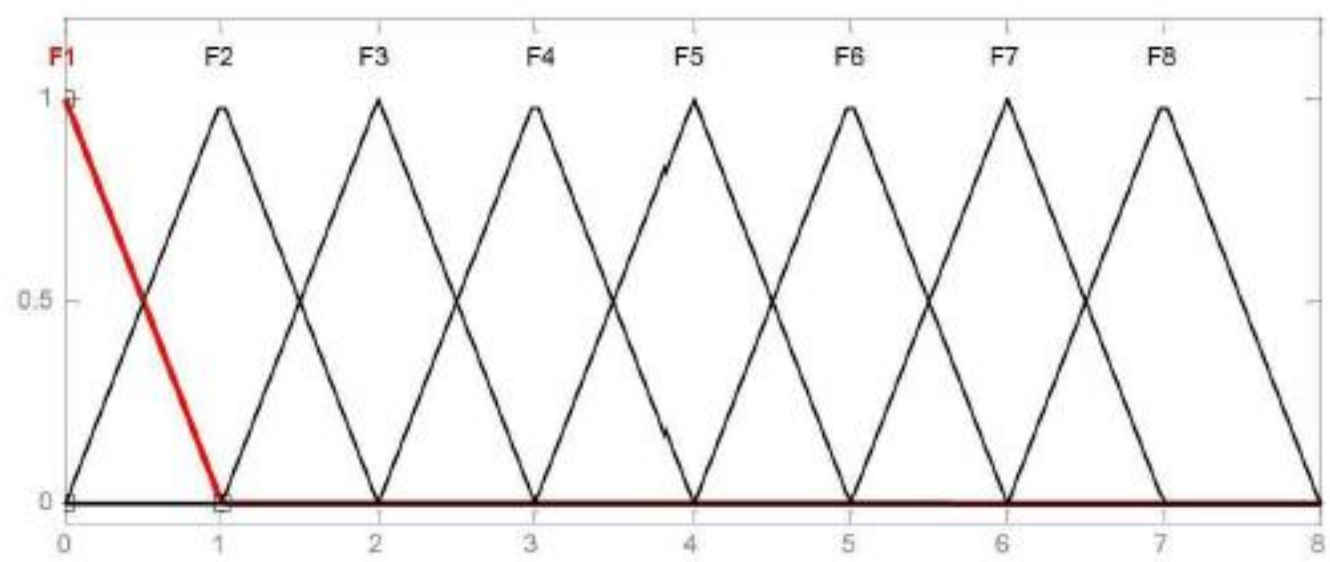

Fig. 3: Input membership function of tourist attraction parameters $\left(f_{\text {ext }}\right)$

The membership functions are subsequently processed by the inference engine that retrieves data in the form of fuzzy rules contained in the knowledge-base.
IF tourist attraction parameters $\left(f_{\text {ext }}\right)$ THEN (tourist attraction output $=\boldsymbol{K} \boldsymbol{i} \boldsymbol{j})$, where $[i, j]=[1,2]$. The truth table consisting of a set of linguistic variable that establish the knowledge base is depicted in Table 1. 
Table 1: Rule Base Table

\begin{tabular}{|c|c|c|c|c|c|}
\hline & \multicolumn{5}{|c|}{ FUZZIFICATION } \\
\hline & \multicolumn{5}{|c|}{ Tourist Attraction } \\
\hline \multirow{9}{*}{ 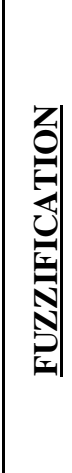 } & TA parameter & $\mathbf{P}_{1}$ & $\mathbf{P}_{2}$ & $\mathbf{P}_{3}$ & $\mathbf{P}_{4}$ \\
\hline & $f_{1}$ & $\mathrm{~K}_{11}$ & $\mathrm{~K}_{21}$ & $\mathrm{~K}_{31}$ & $\mathrm{~K}_{41}$ \\
\hline & $f_{2}$ & $\mathrm{~K}_{12}$ & $\mathrm{~K}_{22}$ & $\mathrm{~K}_{32}$ & $\mathrm{~K}_{42}$ \\
\hline & $f_{3}$ & $\mathrm{~K}_{13}$ & $\mathrm{~K}_{23}$ & $\mathrm{~K}_{33}$ & $\mathrm{~K}_{43}$ \\
\hline & $f_{4}$ & $\mathrm{~K}_{14}$ & $\mathrm{~K}_{24}$ & $\mathrm{~K}_{34}$ & $\mathrm{~K}_{44}$ \\
\hline & $f_{5}$ & $\mathrm{~K}_{15}$ & $\mathrm{~K}_{25}$ & $\mathrm{~K}_{35}$ & $\mathrm{~K}_{45}$ \\
\hline & $f_{6}$ & $\mathrm{~K}_{16}$ & $\mathrm{~K}_{26}$ & $\mathrm{~K}_{36}$ & $\mathrm{~K}_{46}$ \\
\hline & $f_{7}$ & $\mathrm{~K}_{17}$ & $\mathrm{~K}_{27}$ & $\mathrm{~K}_{37}$ & $\mathrm{~K}_{47}$ \\
\hline & $f_{8}$ & $\mathrm{~K}_{18}$ & $\mathrm{~K}_{28}$ & $\mathrm{~K}_{38}$ & $\mathrm{~K}_{48}$ \\
\hline
\end{tabular}

After the fuzzification and solving for tourist attraction coefficients using the Mamdani inference engine, the resulting fuzzy output need to be converted into a crisp output. This is conducted at the deffuzzification stage using the Mamdani's Center of Gravity method (COG). This defuzzification method consists of calculating the abscissa of the COG of the resulting membership function $\mu r$ of the composition phase. The degree of membership for the four output variables $\left(K_{11}, K_{12}, K_{21}\right.$ and $\left.K_{22}\right)$ is illustrated in Figure 4.

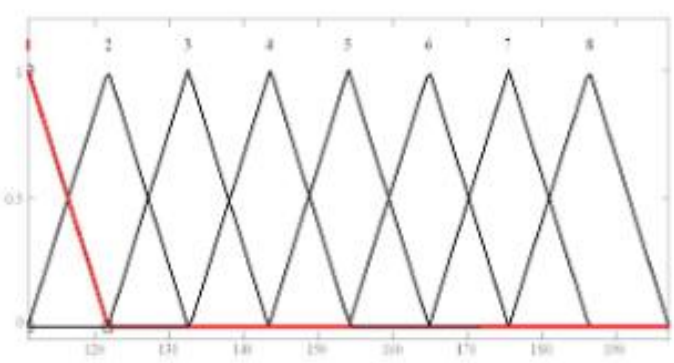

(a) Fint pole coefficient $K_{11}$

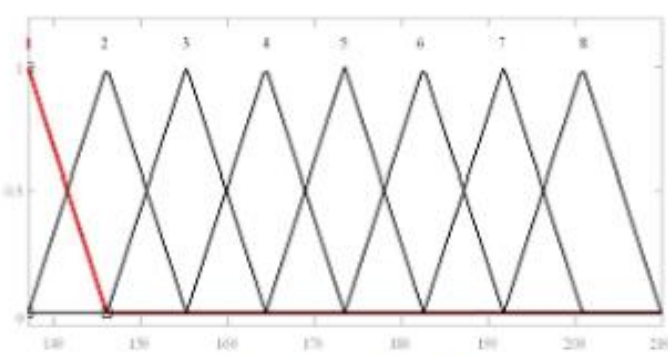

(b) Second pole coefficient $K_{12}$

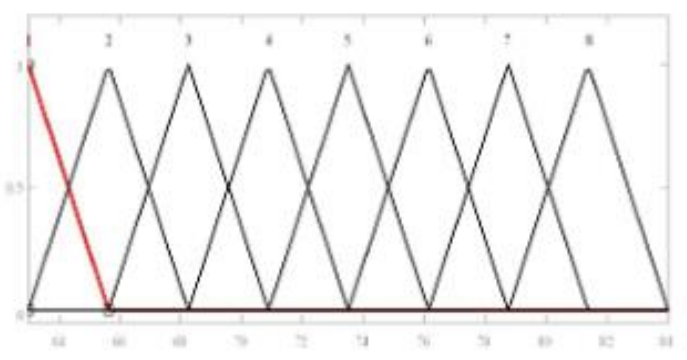

(c) Third pole coefficient $K_{21}$

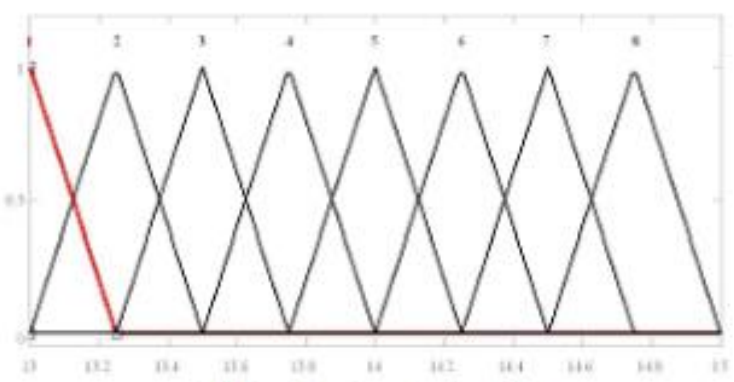

(d) Fourth pole coefficient. $K_{22}$

Fig. 4: Output membership function for the tourist attraction parameters $K_{11}, K_{12}, K_{21}$ and $K_{22}$

After applied the fuzzy logic methodology to optimize this placement the 'Striped Strategy' reinforces the idea of the waterfront acting as a threshold in a number of ways. In addition to the similar formal organization of the piers, the striped strategy provides physical and visual and connections between the city and harbour with a repetition of narrow open areas and promenades. The narrow dimensions of the promenades and low building heights relate more to the scale of the human body, making them beneficial for successful mixed use buildings. Pedestrians will be encouraged to meander through the promenades as they walk through many axes connecting the city and the harbor. The striped pier-like language also creates opportunities to increase surface area as the piers extend into the harbour, and simultaneously increase the waters edge to walk along. Increasing the waters edge is taken one step further, by inverting the extending piers into narrow canals or water features stretching inland toward the grid. Strips can also extend into the adjacent vacant sites within the grid. However, as an early conclusion, such extensions weaken the waterfront area as the threshold between the city and harbour. Now that the chosen strategy has been described, we can look more closely at the specific site for this paper. A detailed design sequence illustrates the process of dividing the site into strips and breaking the long buildings into shorter rectangles. By making further divisions, the ground plane and buildings have a greater connection to the human scale and creates shorter axis that run parallel to the harbours edge. Possible extensions of the striped language into the city grid is an option, but does not support this argument powerfully. This city plan also sets up the site specific master plan that allows one building to be further developed using thresholds. While the brief nature of this method does not allow for the kind of in-depth analysis required to pronounce either the private or public strategies of economic redevelopment profiled here the most successful or beneficial, it is intended to suggest that both exist and must be acknowledged and reckoned with by any scholars or practitioners or tourism, urban theory or local and/or regional economic redevelopment. If it is still too early to tell which strategy, the public or private, will prove the most successful in the long run, what should be considered is whether or not these two can 
work together (or can work separately in the same place) toward a common good for not only visitors or potential residents, but also for long-time local dwellers with strong ties to a given area as well. Only by taking an interdisciplinary approach (considering the power of cultural heritage narratives as well as statistics and demographics, for example) and thinking outside the proverbial box of tourism studies, musicology and traditional economic redevelopment approaches can a truly sustainable and socially equitable postindustrial urban environment be established. Based on above methodology striped strategy has the following advantages; striped language connecting city and harbor, extend grid axis to harbor, striped public park, low horizontal buildings, maintain general equality within typography and Establish site specific formal element. Exploring one strategy has also generated many site specific design influences, which are unique to Halifax's past and present conditions.

Using the traditional pier language for the public plinths creates the opportunity to shift the public and private programs together. Using a consistent language for the plinths also allows the building aesthetics of the private volumes above, to remain flexible for different architects to design. The use of vertical and horizontal planes has been chosen because of the similarity to the rectangular piers pushing out into the water, and the striped language of the strategy. This also creates consistent park elements that extend into the interior spaces of the plinth. The influences of the surrounding park on the building organization have become a predominant conclusion when combining private and public spaces. Therefore based on above discussion and based on fuzzy logic optimization Striped Strategy is the best alternative for Halifax.

\section{Results}

\section{Undeveloped Industrial Site: Halifax, Nova Scotia, Canada}

Halifax peninsula still remains Atlantic Canada's largest port city [10-11]. With a long history, like many other coastal cities, much of the waterfront property is used by the Department of National Defense, the shipping industry, and transportation [7-9]. Making the left over accessible waterfront invaluable [10-13]. The strip of waterfront, once preoccupied with the fishing industry, is now diverse and lively, accommodating tourism, commercial, limited residential and industrial uses. A popular boardwalk along the shore line brings visitors and locals together, providing an atmosphere where pedestrians can move freely. To fully comprehend the importance of the Halifax peninsula, and more specifically the publicly accessible waterfront, it is necessary to acknowledge the physical attributes and population trends of the area. From the previous maps and images of Halifax and the surrounding HRM area, we can begin to realize the geographical limitations the urban core has when operating on a city scale [13]. Figure 5 shows the Nova Scotia in a map.

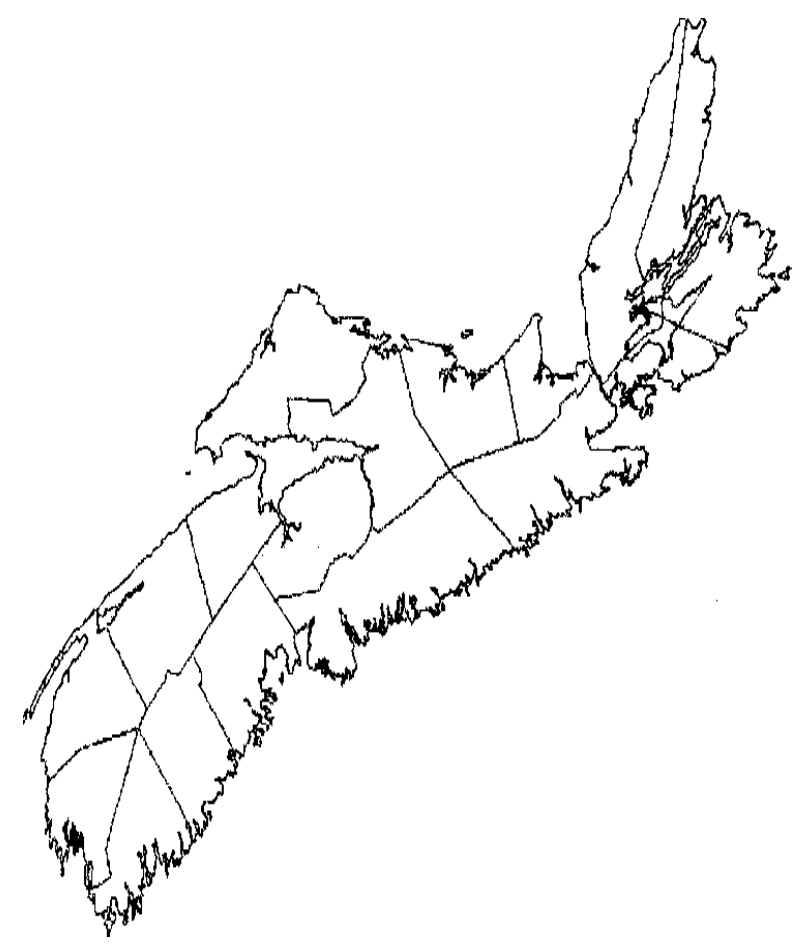

Fig. 5: Nova Scotia, Canada

Because the peninsula is restricted in size, any large scale development in the city or on the small area of waterfront will have a major impact on the image of the city and the opinions of Halifax's population. In addition to geographical limitations, strong ties to the traditional character and heritage buildings of downtown, especially the public waterfront, creates a difficult context for future development to deal with. The City of Halifax was established in 1841, and used to be the capital of the province of Nova Scotia and shire town of Halifax County. Halifax was the largest city in Atlantic Canada, now it is no longer an incorporated city [11-13]. On April 1, 1996, the government of Nova Scotia dissolved the City of Halifax, and amalgamated the four municipalities within Halifax County and formed Halifax Regional Municipality, a single-tier regional government covering that whole area. Here the lack of development and population of Halifax becomes evident. Although the pedestrian area is wide in comparis on to some larger cities, the inclusion of developed parks and buildings shows Halifax's reluctancy, or perhaps indecisiveness when considering further redevelopment. The wide width of the pedestrian zone creates many possibilities for integration of parks and buildings. Similar to Baltimore, the city grid changes to pedestrian movement as it touches the pedestrian zone, and there are also two elevated pedestrian walkways [10-13]. In contrast to Battery Park, little overlap of the grid and pedestrian zone occurs. Figure 6 shows Google earth Halifax. 


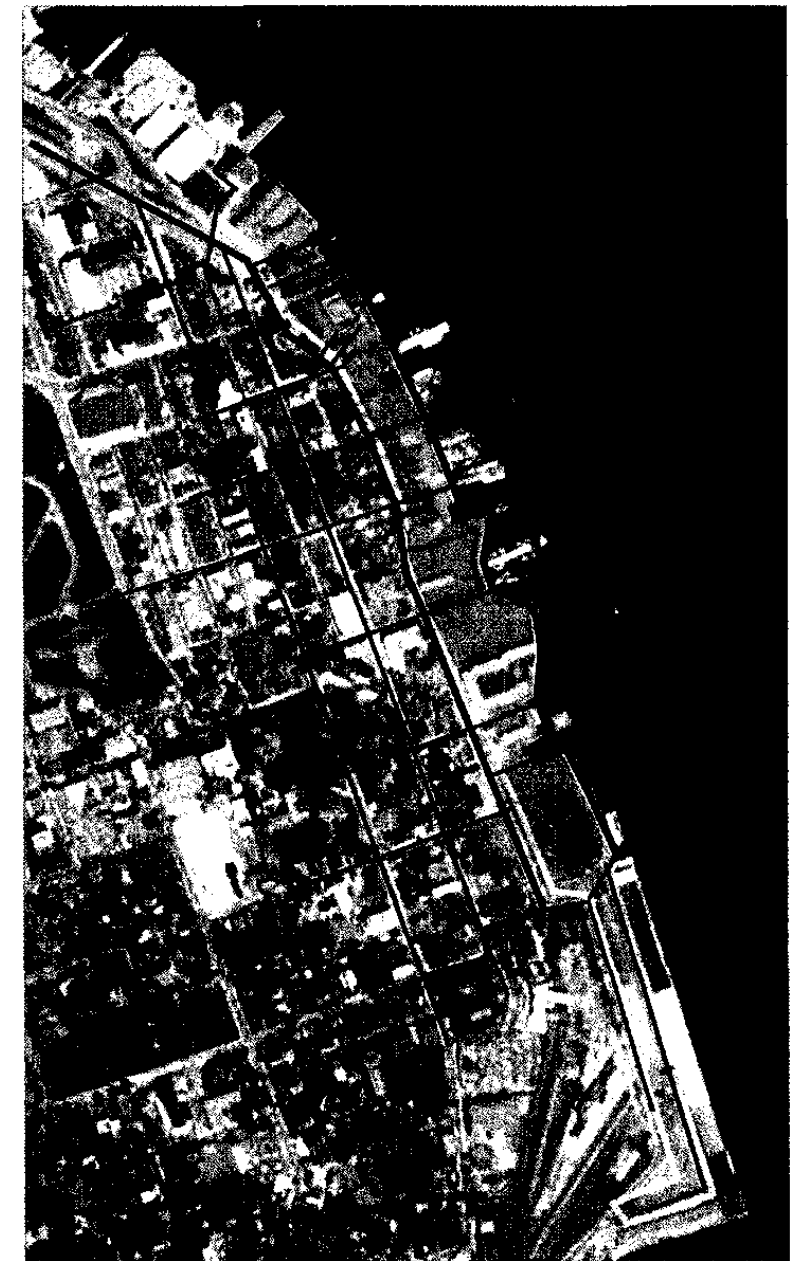

Fig. 6: Google Earth Halifax

\section{Conclusion}

Based on above discussion and Mamdani fuzzy logic optimizer the researcher conclude that, stripped strategy which applied to waterfront city is one of the best places that must be managed for tourist attractions . tourist attraction parameters strategy was used to achieve a stable and asymptotic attract, while the fuzzylogic technique added intelligence to the optimize select strategy through automatic tuning of the tourist attraction coefficients. Simulation results demonstrated the validity of the Halifax with asymptotic waterfronts tourist attraction based on stripped methodology. It is important to state that there are general principles which may add to the discourse on waterfront and its application to tourist economy and education, and there are strategy specific principles. The researcher has explored the strategy specific principles in greater detail as a way to test the private public combinations. General principles write as follows; Waterfronts must be mixed use developments and pedestrian dominated, conceive waterfront as a threshold between city grid and harbor, choose strategy based on historic and contemporary site conditions, strategies should include at least four programmatic elements: Public Park, public plinth, private shared, private residential, Buildings must be mixed use, use strategy to inform building volume and program organization, establish at least one formal element that ties the strategy together. The researcher has chosen the Striped Strategy not only because Halifax's waterfront historically consisted of many piers, but more importantly, because so many piers still exist today.

\section{Acknowledgment}

The authors would like to thank the anonymous reviewers for their careful reading of this paper and for their helpful comments. This work was supported by the Islamic Azad University (IAU).

\section{References}

[1] Ando, Tadao. 1984. Tadao Ando: Buildings Projects Writings. New York: Rizzoli International Publications.

[2] Another Form of Intervention. Olivetti Showroom. ww.studiocleo.com/gallerie/scarpa/ olivetti.html

[3] Answers.com. Ludwig Mies van der Rohe. www.ans wers .co m/topic/ludwig-mies-vander-rohe.

[4] Art, Design and Visual Thinking. De Stijl. char.txa.cornell.edu/art/decart/destijl/decstijl. htm.

[5] Arts and Crafts Society. http:/lforum.artscrafts.com/eve/forums/a/tpc/f/3086045532/ $\mathrm{m} / 9371038772$.

[6] Blue Trout Graphics. www.btrout.com/port/mondrian/para.jpg

[7] BluPete. History of Nova Scotia. www.blupete.com/Hist/NovaScotiaBk1/Part S/Map s/halifax.gif

[8] Breen, Ann, and Dick Rigby. 1996. The New Waterfront: A World Urban Success Story.London: Thames and Hudson.

[9] Canada Vacation Planner. Halifax Metro Area. www.nova-scotia-kanada.de/enlhalifax/index.html.

[10] Farr, Douglas. 2008. Sustainable Urbanism: Urban Design with Nature. New York: John Wiley \& Sons Inc.

[11] Frederick, Matthew. 2007. 101 Things I Learned in Architecture School. Cambridge, Massachusetts: MIT Press.

[12] Google Earth. www.earth.google.com

[13] Halifax Regional Municipality. www.halifa x.ca/regionalplanning/lmages/HRM ma plg.jpg. Hayward, Catherine. 1984. L'Invention du Pare. Paris: Graphite Editions. 
[14] L. A. Zadeh, "Toward a theory of fuzzy information granulation and its centrality in human reasoning and fuzzy logic," Fuzzy Sets and Systems, Vol. 90, No. 2, pp. 111-127, 1997.

[15] L. Reznik, Fuzzy controllers: ButterworthHeinemann, 1997.

[16] J. Zhou and P. Coiffet, "Fuzzy control of robots," IEE proceeding Control Theory and Applications, Vol. 147, No. 2, 2002, pp. 1357-1364.

[17] S. Banerjee and P. Y. Woo, "Fuzzy logic control of robot manipulator," Second IEEE conference on Control Applications, 2002, pp. 87-88.

[18] K. Kumbla, E. Tunstel and M. Jamshidi, "Soft computing for autonomous robotic systems," Computers and Electrical Engineering, Vol. 26, No. 1, pp. 5-32, 2000.

[19] C. C. Lee, "Fuzzy logic in control systems: fuzzy logic controller. I," IEEE Transactions on systems, man and cybernetics, Vol. 20, No. 2, pp. 404-418, 1990.

[20] R. J. Wai, R. Y. Duan, W. H. Wang and L. W. Liu, "Implementation of artificial intelligent control in single-link flexible robot arm," IEEE International Symposium on Computetional Intelligence in Robotics and Automation, 2003, pp. 1270-1275.

[21] R. J. Wai and M. C. Lee, "Intelligent optimal control of single-link flexible robot arm," IEEE Transactions on Industrial Electronics, Vol. 51, No. 1, pp. 201-220, 2004.

\section{Authors' profiles}

Shekufe Mottaghi is the PHD student of psychology, the professor of shahrekord non-profitable university

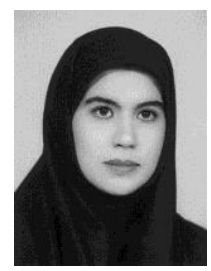

Fatemeh Farhadi is a Master student of Architect engineer researcher. Her research activities deal with the waterfront city and Artificial intelligence.

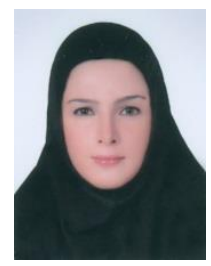

Samira Dokohaki is a Master student of Architect engineer researcher. Her research activities deal with the waterfront city and Artificial intelligence.

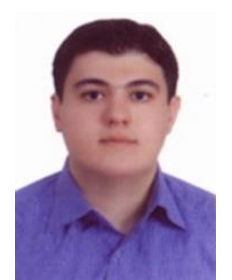

Mohammad Mohsen Farhadi is a civil engineer researcher. His research activities deal with the water front city.

How to cite this paper: Shekufe Mottaghi, Fatemeh Farhadi, Samira Dokohaki, Mohammad Mohsen Farhadi,"Artificial Intelligence Design Waterfronts and Particular Places Management to Improve Relationships between People", International Journal of Intelligent Systems and Applications(IJISA), vol.5, no.9, pp.58-66, 2013. DOI: 10.5815/ijisa.2013.09.07 